\title{
Discussion on the Preparation Process of BFRP Reinforced Concrete Column Test
}

\author{
$\mathrm{Ke} \mathrm{Li} \mathrm{i}^{1, a}$ \\ ${ }^{1}$ Department of Civil Engineering, Sichuan College of Architectural Technology,Deyang ,China \\ a361686061@qq.com
}

\begin{abstract}
Keywords: BFRP; Strengthening; Concrete; Axial compression columns.
Abstract. The research and practice have proved that it is effective, easy to construct, and reliable quality to reinforce the concrete column with fiber cloth.Through the study of using FRP reinforced concrete cylindrical experimental process from domestic and foreign scholars, the preparation process of concrete column reinforced with BFRP is discussed.This paper summarizes the matters needing to be prepared before the test of concrete columns reinforced with BFRP.It can be used as a guide for the experimental study of concrete columns reinforced with BFRP.
\end{abstract}

\section{Introduction}

Column is the most important load-bearing component in the building structure.Mainly bear the load of beam and plate, and transfer the load to the foundation.It directly affects the safety and applicability of the whole building.But there are some problems of the concrete column:Lack of adequate energy dissipation and lateral restraint; the shear strength, flexural strength and ductility of the column are not enough,it is easy to be damaged in the earthquake.It is not safe for people's lives and property.The effective way to solve these problems is to reinforce the concrete column[1].

A lot of practice and research shows that FRP reinforced concrete column is a kind of very effective reinforcement method.After the concrete column reinforced by this method,the lateral deformation of the core concrete is restrained by the external fiber cloth. So that the core concrete is in the three state of confining pressure. The strength and ductility of the concrete columns are improved in different degrees.

BFRP is a new and efficient material for structural reinforcement,it has the advantages of high strength, low weight, high temperature resistance, good chemical stability, and good cooperation with concrete, the price is only $1 / 5$ of carbon fiber (CFRP). Therefore, it is of great significance to study the performance of BFRP reinforced concrete. This paper summarizes the matters needing to be prepared before the test of concrete columns reinforced with BFRP.It can be used as a guide for the experimental study of concrete columns reinforced with BFRP.

\section{Specimen Design}

Existing experimental studies have shown that when the concrete column is under pressure,the expansion and penetration of the concrete cracks are directly affected because of the existence of friction resistance on the end face of the column[2]. This kind of friction resistance determines the degree of end restraint. The greater the friction resistance, the stronger the binding strength, the higher the strength test value.Although the surface of the concrete column can be coated with wax or placed in the gasket in order to reduce the friction between the column and the pressure plate, but it is very difficult to completely eliminate.

According to Saint Venant principle, the vertical compressive stress and horizontal binding force of the compression face of the column have significant influence on the stress state near the end face,the middle part of the column is close to the uniaxial compressive stress state.The axial compressive strength of concrete columns decreases monotonically with the increase of height to width $\operatorname{ratio}(\mathrm{L} / \mathrm{b})$, when the $\mathrm{L} / \mathrm{b}$ is between $2 \sim 3$, the contact surface friction constraint can be eliminated and the additional eccentricity can be avoided[3].Therefore, in the design of the test, the $\mathrm{L} / \mathrm{b}$ of the concrete column were taken as 3 . 
If we want to study the effect of concrete strength and the amount of basalt fiber cloth reinforcement on the concrete column restraint effect, all specimens are not suitable for stirrups and reinforced steel bars.All the specimens with fiber cloth paste form for all parcels,as shown in Fig.1.

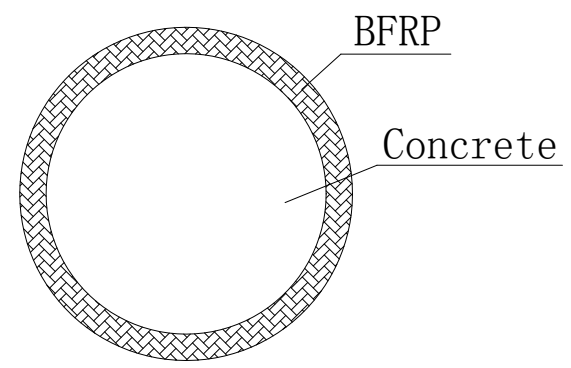

Fig. 1 Cross Section of the Specimen Form

The test is for concrete cylinder,with wood is not easy to make.It can be customized steel die, but the high cost of steel mold.Therefore, the concrete cylinder test mold can be customized with PVC water supply pipe,back plane using PVC board,then using the special glue to glue the two materials, the integrity can be guaranteed.Concrete mould as shown in Fig.2.

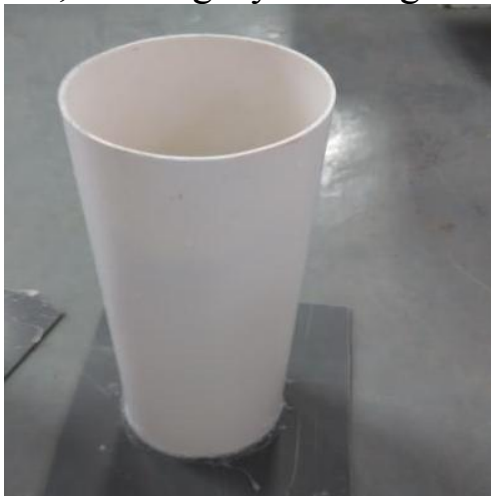

a) Small Size

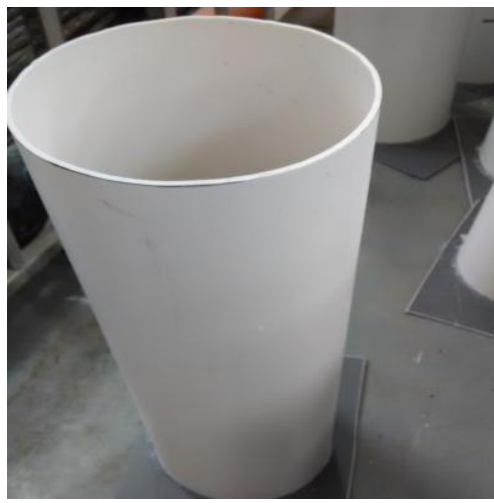

b) Large Size

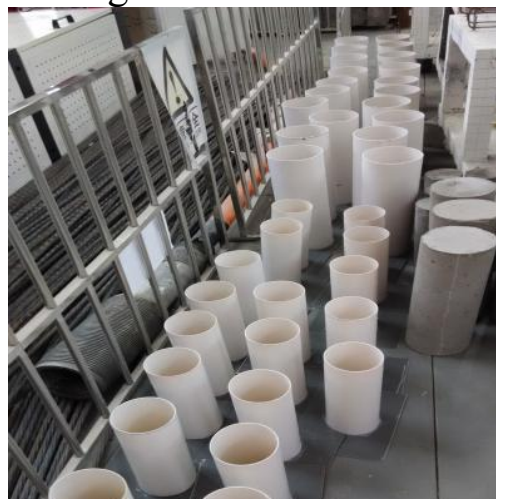

c)Part Mold

Fig.2 Concrete Mold Figure

\section{Material Test}

The materials used in this experiment include concrete, BFRP and epoxy resin.The mechanical parameters of these materials directly affect the test data, so it is necessary to test the mechanical parameters of the materials.

The concrete material test was conducted using a cube standard test piece with a side length of 150 $\mathrm{mm}$,in the standard conditions for conservation,measure the 28 day cube compressive strength values. The performance of epoxy resin can be detected by SiChuan construction engineering quality inspection center. This paper mainly introduces the test method of BFRP mechanical properties

BFRP Material Test.Put epoxy resin on the BFRP at room temperature and naturally dry.Then according to the Test method for tensile properties of orientation fiber reinforced polymer matrix composite materials(GBT3354 - 2014)[4] and Carbon fiber sheet for strengthening and restoring structures(GB/T 21490-2008)[5] determined the BFRP cloth cut into strips $15 \mathrm{~mm}$ wide, 230mm long.The fixture is a metal sheet having a length of $50 \mathrm{~mm}$ and a thickness of $2 \mathrm{~mm}$,its width is slightly larger than the width of the specimen.

The well-made BFRP specimens were naturally cured for 7 days,then tested the specimens by tensile test machine.The experiment using continuous loading way, the loading speed control in 2 $\mathrm{mm} / \mathrm{min}$.After the experiment, the stress - strain curve of BFRP is plotted based on the measured load - deformation value.Then derived the elastic modulus of BFRP.Fig.3 and Fig.4 are the results of basalt fiber cloth before and after the test. 


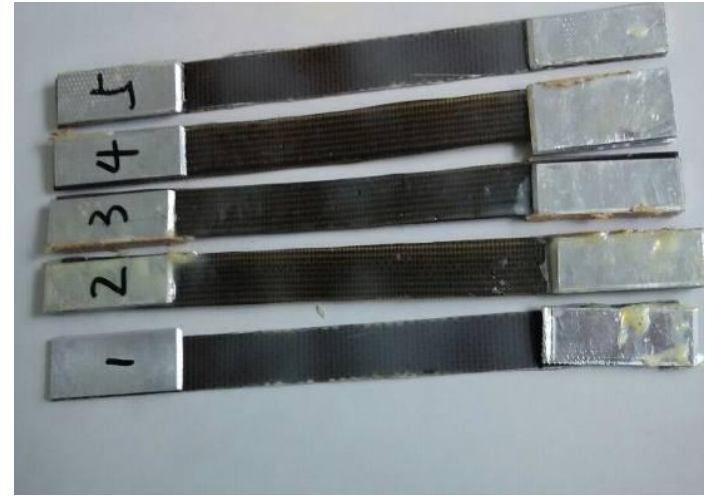

Fig.3 Before the Test

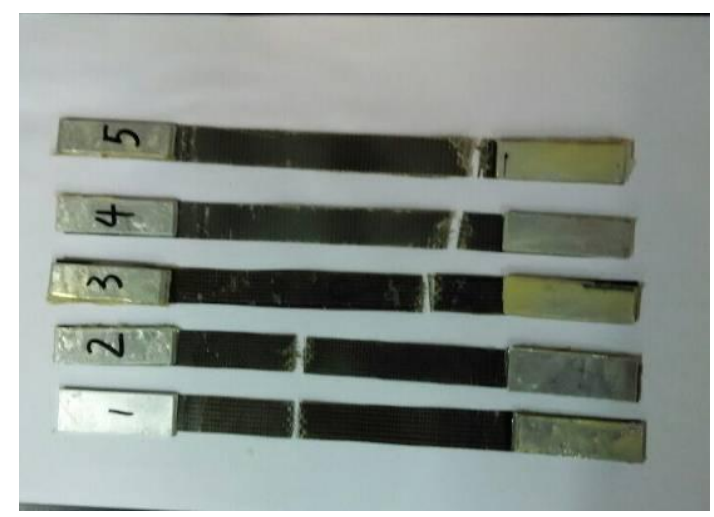

Fig.4 After the Test

As can be seen from figure 4, the failure of BFRP cloth is the tensile failure of the middle section of the specimen.Before the damage we can hear the sound of the fibre tow sheared off, then "bang" is heard, fiber cloth was breaked.It shows obvious brittle fracture characteristics.And the test data after the test are recorded in Tab.1.As can be seen from Fig.5, BFRP cloth belongs to linear elastic material, and its stress-strain curve is approximately a straight line.

Tab.1 The Physical and Mechanical Properties of BFRP

\begin{tabular}{ccccc}
\hline $\begin{array}{c}\text { Sample } \\
\text { number }\end{array}$ & Maximum tensile test $(\mathrm{KN})$ & Elongation $(\%)$ & $\begin{array}{c}\text { Maximum tensile stress } \\
(\mathrm{MPa})\end{array}$ & $\begin{array}{c}\text { Elastic modulus } \\
(\mathrm{GPa})\end{array}$ \\
\hline 1 & 1996.85 & 2.13 & 1210.21 & 56.82 \\
2 & 2055.33 & 2.52 & 1245.65 & 49.43 \\
3 & 2231.63 & 2.64 & 1352.51 & 51.23 \\
4 & 2132.01 & 2.35 & 1292.12 & 54.98 \\
5 & 1870.61 & 1.86 & 1133.70 & 60.95 \\
Average & 2057.29 & 2.30 & 1246.84 & 54.68 \\
value & & & \\
\hline
\end{tabular}

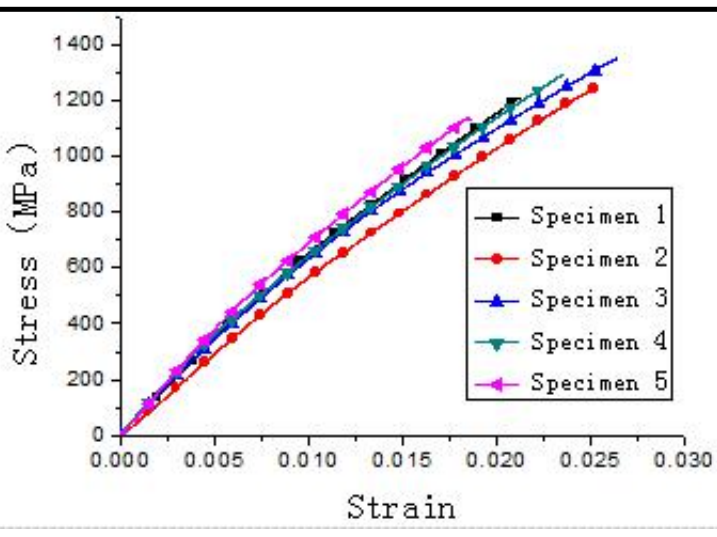

Fig.5 Stress Strain Relationship of BFRP Material

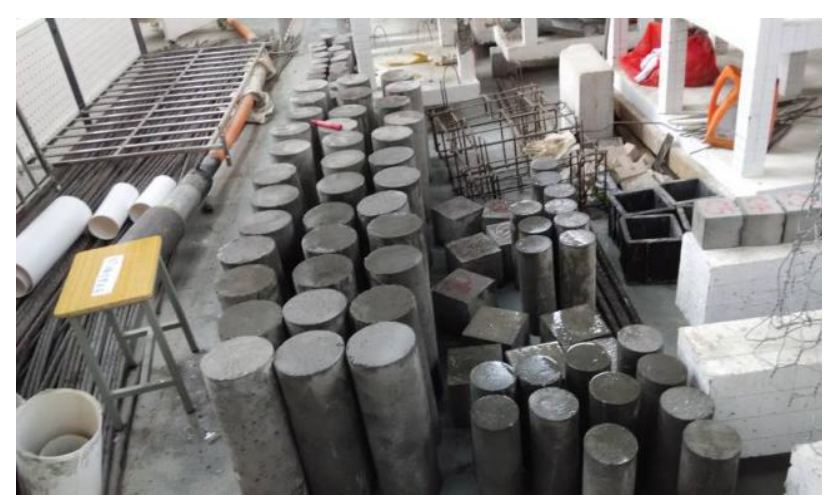

Fig.6 Concrete Specimens

\section{Specimen Making}

The concrete was stirred with a blender,after pouring with a small vibration rod vibration molding.Three days after the demolition of mold, the number of specimens at the same time to fill a vacancy on the surface flaw of specimen. Then put the specimen in the laboratory, water conservation. The concrete specimens is shown in Fig.6.

Before the paste BFRP cloth, first of all to maintain good concrete specimens for processing. The treatment of the specimen and the BFRP cloth paste in strict accordance with the relevant provisions of the CECS 146:2003[6]. Before the test piece paste BFRP cloth,in order to ensure the coordination between BFRP and concrete, first with the grinding machine to remove dust from the loose surface of concrete and polish until the exposed coarse aggregate, and then scrub clean with acetone, to be dry after the beginning of the paste BFRP cloth.

First, apply the epoxy resin, try to make the surface smooth. When the BFRP cloth is wrapped, the oblique force of fiber is avoided,always pay attention to the fiber straightened and taut.Timely removal of bubbles in order to ensure that the fiber can play a role.And then evenly coated with a 
layer of epoxy resin on the BFRP cloth,so that the full penetration of BFRP cloth.Finally scrape off the excess epoxy resin.After surface resin curing,checking is there any floating,expansion or peeling on the BFRP cloth.If so, repair it immediately.

In order to avoid the damage of the lap joint,the overlap length must be guaranteed,at least $150 \mathrm{~mm}$.In order to prevent the failure of the specimen end, two layers of BFRP cloth were added at the end of the specimen.Place the concrete column in a cool and dry place after the BFRP cloth is finished.After sufficient curing, the single load experiment of BFRP confined concrete member is carried out.It can also be used as a strain gauge to measure the lateral deformation and vertical deformation of concrete specimens during the test.The specimen making process is shown in Fig.7.

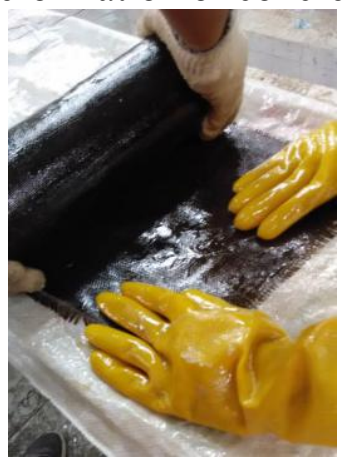

a) Paste BFRP

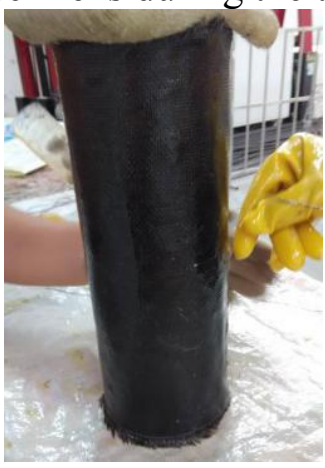

b) Scrape off the Excess Resin

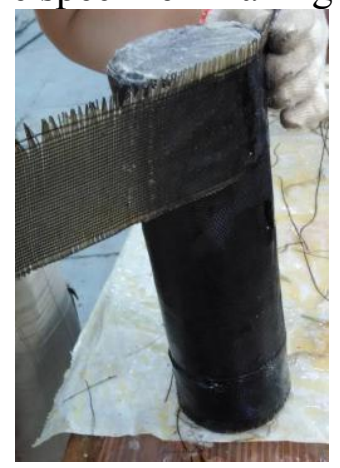

c) Paste Reinforced Layer

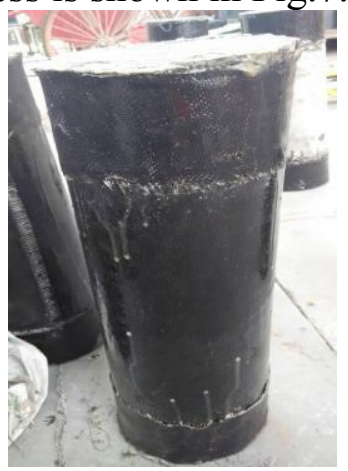

d) The Good Specimen

Fig.7 Specimen Making Process

\section{Conclusions}

This paper summarizes the matters needing to be prepared before the test of concrete columns reinforced with BFRP.Mainly introduces the testing method of BFRP material property test,the method and the matters needing attention of the concrete column sticking BFRP cloth.Through the tensile test of BFRP fabric,it is concluded that although the tensile strength of BFRP cloth is high, the BFRP is a linear elastic material, and its stress-strain curve is approximately a straight line. When the concrete specimen is sticking BFRP cloth, it is necessary to pay attention to straightening and tightening the fiber at any time, so as to ensure that the fiber can fully play a role.Also to ensure that the BFRP cloth has a certain length of lap, to prevent the end of the specimen failure.It can be used as a guide for the experimental study of concrete columns reinforced with BFRP.

\section{References}

[1] C. Shuangyin, Q. Hongxing, W. Henghua. Structural Reliability Appraisal and Reinforcement Technology[M].China Water Power Press,2002.

[2] Z. Haibo. Test Study on Mechanical Performance of High-strength Concrete Column Confined by CFRP under Axial Load[D].Dalian:Dalian University of Technology,2006.

[3] Q. Jianlin. Experimental Study on the Axially Compressed Circular Concrete Column Confined by Basalt Fiber Reinforced Plastic Sheet[D]. Guangdong University of Technology,2011.

[4] GB/T3354-2014, Test Method for Tensile Properties of Orientation Fiber Reinforced Polymer Matrix Composite Materials[S].

[5] GB/T21490-2008, Carbon Fiber Sheet for Strengthening and Restoring Structures[S].

[6] CECS146 : 2003, Technical Specification for Strengthening Concrete Structures with Carbon Fiber Sheets[S]. 